\title{
Isomerization of $\alpha$-pinene over calcined natural zeolites
}

\author{
Oğuz Akpolat ${ }^{a}$, Gönül Gündüz ${ }^{b, *}$, Fehime Ozkan $^{c}$, Nurgün Beşün ${ }^{b}$ \\ a Department of Bioengineering, Ege University, Bornova, İzmir, Turkey \\ b Department of Chemical Engineering, Ege University, Bornova, İmir, Turkey \\ ${ }^{c}$ Chemical Engineering Department, İzmir Institute of Technology, Urla, İmir, Turkey
}

Received in revised form 18 December 2003; accepted 30 December 2003

Available online 11 March 2004

\begin{abstract}
In this work, isomerization reaction of $\alpha$-pinene was studied over several heat-treated natural zeolite catalysts, rich in clinoptilolite, from Balýkesir-Bigadic region in Turkey in a batch slurry reactor under nitrogen atmosphere. Zeolite samples were calcined at different temperatures such as 300,450 and $600^{\circ} \mathrm{C}$. All catalysts were tested in the isomerization reaction of $\alpha$-pinene and were characterised by nitrogen adsorption experiments, IR, and XRD measurements. Acidity strength and the distribution of Lewis and Bronsted acid sites of the samples were determined. Selectivities to main reaction products, camphene and limonene, and reaction kinetics were investigated. Catalytic activity, that is total conversion of $\alpha$-pinene, of heat-treated samples decreased with increasing calcination temperatures. Selectivity to limonene is dependent on $\alpha$-pinene conversion at high conversion levels while the selectivity to camphene is not. The formation of heavy products increased with treatment temperature. It was seen that $\alpha$-pinene consumption could be described by a first-order kinetics.
\end{abstract}

(c) 2004 Elsevier B.V. All rights reserved.

Keywords: $\alpha$-Pinene; Isomerization; Camphene; Limonene; Natural zeolite; Catalyst characterization; Clinoptilolite; Kinetic modelling

\section{Introduction}

Monoterpenes are widely used in the pharmaceutical, cosmetic and food industries as active components of drugs and ingredients of artificial flavours and fragrances. $\alpha$-pinene, one of the most widespread bicyclic monoterpenes, is a very reactive substrate, being abundant in the monoterpene fraction of natural essential oils such as pine and eucalyptus resins. Double-band migration in cyclic alkenes is a suitable method to characterize catalytic sites [1]. The liquid phase isomerization of $\alpha$-pinene over solid catalysts is a well-known reaction and is utilized very often as a model reaction for acid-base properties of many catalysts. In the isomerization of $\alpha$-pinene over heterogeneous catalysts, different monoterpene products such as bi- and tricyclic products ( $\beta$-pinene, tricyclene, camphene, etc.) and monocyclic products (limonene, $p$-cymene, $\alpha$ - and $\gamma$-terpinenes, terpinolenes, $\alpha$ - and $\beta$-phellandrenes, etc.) are formed (Fig. 1). The selectivity is highly dependent on

\footnotetext{
* Corresponding author. Tel.: +90-232-388-4000/2292; fax: +90-232-388-7776.

E-mail address: gunduz@eng.ege.edu.tr (G. Gündüz).
}

the type of the heterogeneous catalyst used in the isomerization reaction. Among the catalysts reported are titanium dioxide [2-7], clays [8-10], halloysite [11,12], activated carbon [13], synthetic zeolites [14-17] and silica supported rare earth oxides [18-20] and natural zeolites [21-27] and sulphated zirconia [28]. The structure, specific surface area and distribution of Lewis/Brönsted acidity of zeolites, which is detrimental to catalytic properties, can be changed to a great extent by acidic and thermal treatment. Acidity and size effects play an important role on selectivity ratio of bi- and tricyclic compounds to monocyclic products.

Zeolites provide high activity and unusual selectivity in a variety of acid-catalysed reactions. Most of the reactions are caused by the acidic nature of zeolite. Heat treatment changes the acidity of zeolite. The characteristic that separates zeolites from all-silica minerals is the substitution of metals other than silicon into the crystalline framework, which is aluminium in this case. The replacement of $\mathrm{SiO}_{4}$ tetrahedra by the $\left[\mathrm{AlO}_{4}\right]^{-1}$ tetrahedra in the zeolite framework causes excess negative charges and cations are needed to neutralize them. Compensation of the negative charge by associated cations such as $\mathrm{H}^{+}, \mathrm{Na}^{+}, \mathrm{K}^{+}, \mathrm{Ca}^{2+}, \mathrm{NH}_{4}^{+}$ generates the acid sites. The catalytic activity of the zeo- 


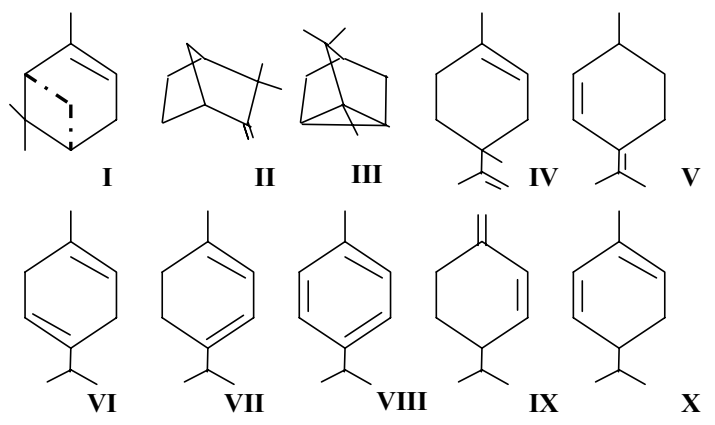

Fig. 1. I: $\alpha$-Pinene, II: camphene, III: tricyclene, IV: limonene, V: terpinolene, VI: $\gamma$-terpinene, VII: $\alpha$-terpinene, VIII: $p$-cymene, IX: $\beta$-phellandrene, $\mathrm{X}$ : $\alpha$-phellandrene.

lites is attributed to the presence of these acidic sites and the proton affinity at the charged framework. The catalytic activity of acid sites may be Brönsted or Lewis character.

If the charge compensating cation associated with the tetrahedral aluminium is hydrogen, the zeolite surface obtains the capacity to act as a proton donor and therefore can serve as a Brönsted acid. often greatly depend on the relative dimensions of the molecules and the pore openings (shape-selective catalysis).

Clinoptilolite is one of the most common, natural zeolite minerals which has wide range of application due to the difficulties in the synthesis, single crystal studies are seldom in the literature. The basic structure of clinoptilolite crystal contains three types of channels with the given approximate dimensions: channel A $(7.2 \AA \times 4.4 \AA)$, channel B $(4.0 \AA \times$ $5.5 \AA)$ and channel $\mathrm{C}(4.1 \AA \times 4.0 \AA)$, where the channels $\mathrm{A}$ and $\mathrm{B}$, which are parallel to each other, are intersected by the channels $\mathrm{C}$, and exchangeable charge-balancing cations $\left(\mathrm{Ca}^{2+}, \mathrm{Mg}^{2+}, \mathrm{Na}^{+}, \mathrm{K}^{+}\right.$, etc. $)$are located in these channels. The channel A is occupied by calcium, magnesium and preferentially by sodium; the channel B is occupied by sodium and preferentially by calcium; and the channel $\mathrm{C}$ is occupied by potassium and these cations are coordinated with the framework oxygen atoms and/or water molecules [33]. Clinoptilolite-rich mineral is made of clinoptilolite crystals and impurities which also function as binding agent; and so it has polydisperse pore size distribution. In recent years,

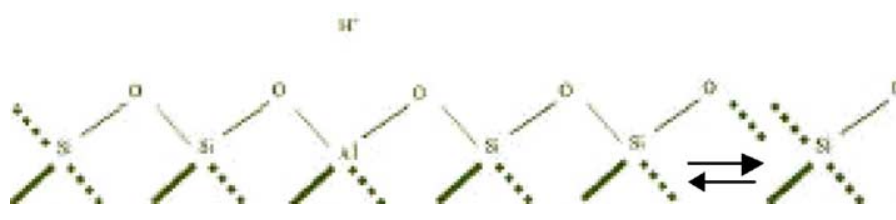

If the zeolite is heated to a temperature higher than $550{ }^{\circ} \mathrm{C}$ formation of Lewis acid site and zeolitic water occur. According to model of Ward [29], two Brönsted acid sites are required to a form a single Lewis (electron acceptor) acid site

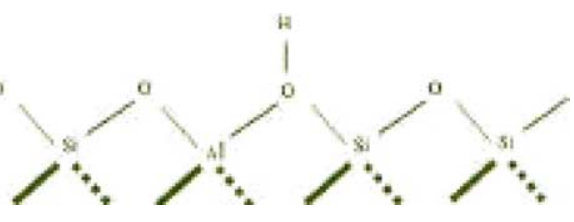

clinoptilolite-based natural zeolite has great importance in the heterogeneous catalytic reactions [21-25,27].

In the isomerization of $\alpha$-pinene, it is suggested in the literature that strong acid sites and high temperatures favour the monocyclic products of $p$-menthadienic structure and

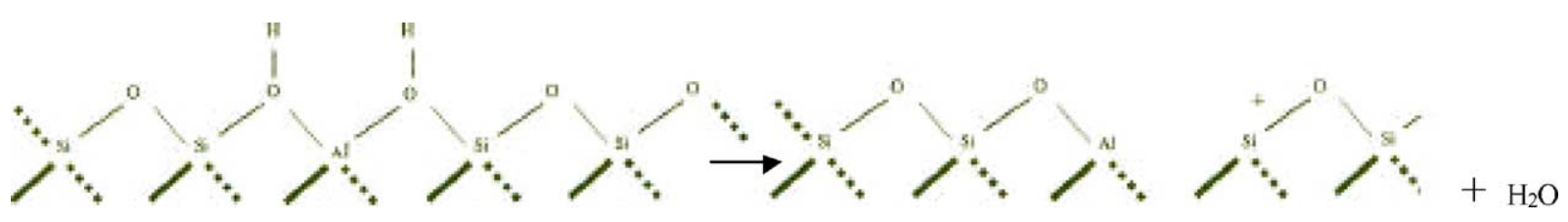

Adsorption of pyridine on Brönsted and Lewis sites gives characteristic infrared bands at 1545 and $1450 \mathrm{~cm}^{-1}$, respectively. Pyridine adsorption studies show that acid site population change with calcination temperature of zeolite. For instance, the intensity of the band at $1545 \mathrm{~cm}^{-1}$ increases with the treatment temperature up to $600 \mathrm{~K}$, is constant at $600-800 \mathrm{~K}$ and decreases above $800 \mathrm{~K}$ on $\mathrm{NH}_{4} \mathrm{Y}$ zeolites. Lewis acid sites develop above $770 \mathrm{~K}$, which is correlated to tri-coordinated aluminum formed by dehydroxlation of zeolites and increase with temperature [30]. In dehydroxlated zeolites, aluminum ions are easily dislodged from the zeolite structure and exist in the pores in the form of cationic species such as $(\mathrm{AlO})^{+}$or their polymeric form. Lewis acid sites are ascribed to aluminum cations by aluminum dislodgement. On the other hand, as known well, zeolites have small and uniform pores and most of the active sites are located inside this pore system, the selectivities of the catalytic reactions

that weak sites and low temperatures favour the bicyclic products of camphene series [16].

Limonene is more reactive than camphene and therefore can be further transformed into different products such as terpinenes and terpinolenes. Terpinenes and terpinolenes can, in turn, be subsequently disproportioned into $p$-menthenes and $p$-cymene. As known, bimolecular disproportionation reactions require more space, due to the bulky intermediates involved. That is why, $p$-menthenes are not identified over microporous materials. Lopez et al. [14] reported that the wider the pore diameter the higher the production of undesired heavy and unidentified products.

Our research group previously reported many studies on the isomerization of $\alpha$-pinene over clinoptilolite-based natural zeolites [21-25,27]. The objective of the present work is to study the effects of calcination parameters such as temperature and time on the activity and selectivity of heat-treated 
natural zeolite in tuffs rich in clinoptilolite in the isomerization of $\alpha$-pinene.

\section{Experimental study}

\subsection{Catalyst preparation}

Zeolite tuffs rich in clinoptilolite with quartz impurity were obtained from Bigadiç (Balıkesir, Turkey). Prior to thermal treatment they were diminished into a grain size of approximately $0.5 \mathrm{~mm}$. Zeolite samples of $5 \mathrm{~g}$ were washed with distilled water at $25^{\circ} \mathrm{C}($ code 1$)$ or at $50{ }^{\circ} \mathrm{C}$ (code 2) under continuous stirring for $2 \mathrm{~h}$ to remove impurities. After filtration, samples were dried for $24 \mathrm{~h}$ in an oven at $160^{\circ} \mathrm{C}$ in vacuum, and subsequently calcined at different temperatures such as 300,450 , and $600^{\circ} \mathrm{C}$ for different durations $(60,180 \mathrm{~min})$. The samples were named so that the names showed the preparation conditions, respectively ((thermal treatment temperature, ${ }^{\circ} \mathrm{C}$ ) OA (code 1 for washing at $25^{\circ} \mathrm{C}$; code 2 for washing at $50^{\circ} \mathrm{C}$ ) (treatment time, min)), except natural zeolite which is only heated at $160{ }^{\circ} \mathrm{C}$ shown by (0000A0000).

\subsection{Apparatus and reaction}

The catalysts prepared were tested in the isomerization reaction of $\alpha$-pinene. Reaction was carried out at atmospheric pressure under nitrogen flow in a glass reactor with a reflux condenser, an efficient stirrer and a temperature controller (Fig. 2.). An amount of $1 \mathrm{~g}$ of catalyst and $50 \mathrm{ml}$ of wood turpentine (Ortas, Edremit, Turkey) containing 85 wt. $\% \alpha$-pinene were charged in the reactor. The reaction was started by adding the catalyst and all experiments were carried out under isothermal $\left(155^{\circ} \mathrm{C}\right)$ conditions. Fresh catalyst was used for each experiment. Samples of the reaction mixture were taken during the course of the reaction and analyzed by flame ionization detector (FID) of gas chromatography (Hewlett-Packard 5980/2 with $25 \mathrm{~m}$ and $0.32 \mathrm{~mm}$ i.d. HP-FFAP capillary column) connected to a mass spectrometer with electron energy $70 \mathrm{eV}$ and mass rate $35-425 \mathrm{~m} / \mathrm{z}$. Temperature programming (increase at a rate of $2{ }^{\circ} \mathrm{C} / \mathrm{min}$

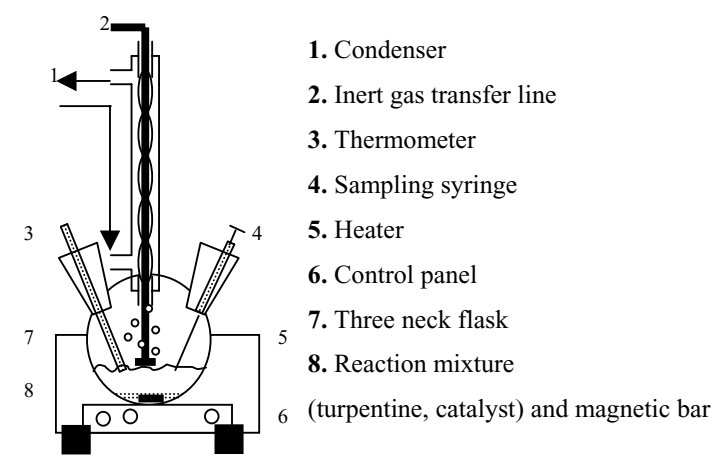

Fig. 2. The schematic diagram of the experimental system. from 60 to $130^{\circ} \mathrm{C}$ and onwards at a rate $3{ }^{\circ} \mathrm{C} / \mathrm{min}$ until $215^{\circ} \mathrm{C}$ ) was applied for separation at $1 \mathrm{ml} / \mathrm{min} \mathrm{N}_{2}$ flow.

\subsection{Catalyst characterization}

Surface areas and pore volumes were obtained from the nitrogen adsorption isotherms measured at $77 \mathrm{~K}$ in a static volumetric apparatus (Coulter Omnisorp 100cx) up to $\mathrm{P} / P_{\mathrm{O}} \sim$ 0.95 .

The chemical analysis of natural zeolite used was done by atomic absorption except gravimetrically analysis of $\mathrm{SiO}_{2}$ and water. The chemical composition found is $74.86 \% \mathrm{SiO}_{2}$, $0.42 \% \mathrm{FeO}, 0.7 \% \mathrm{MgO}, 0.5 \% \mathrm{Na}_{2} \mathrm{O}, 2.71 \% \mathrm{~K}_{2} \mathrm{O}, 9.04 \%$ $\mathrm{H}_{2} \mathrm{O}, 2.42 \% \mathrm{CaO}, 9.35 \% \mathrm{~A}_{2} \mathrm{O}_{3}$ (by weight) for natural zeolite. IR spectrum of the zeolite catalysts were recorded on $\mathrm{KBr}$ wafers (1.2 mg catalyst and $150 \mathrm{mg} \mathrm{KBr}$ ) with a Shimadzu 470 Instrument. IR analysis took place at room temperature and atmospheric pressure. The amount of acid sites on solid surface of catalyst samples was measured by amine titration. Therefore, for titrating the solid acid, $0.1 \mathrm{M}$ diethylamine, of which the $\mathrm{p} K_{\mathrm{b}}$ is 3.00 , in benzene solution was used.

Hammett indicators were used for the measurement of acid strength of some catalyst samples. The acid strength was expressed by the Hammett acidity function $H_{0}$. Lower values of $H_{0}$ correspond to greater acid strength of the solid.

Pyridine adsorption was carried out to identify the acid centers of the catalysts. For this purpose, pyridine was adsorbed on dried samples for 1 day prior to measurements. After that, excess amount of pyridine was vaporized in vacuum for $48 \mathrm{~h}$ at $50^{\circ} \mathrm{C}$. Wafers were prepared by using $\mathrm{KBr}$ disk technique ( $8 \mathrm{mg}$ of catalyst/100 mg of $\mathrm{KBr}$ ).

$\mathrm{X}$-ray diffraction studies were carried out for some catalyst samples on a Jeol JSDX 100S4 diffractometer using $\mathrm{Cu}$ $\mathrm{K} \alpha$ radiation with a $\mathrm{Ni}$ filter.

\section{Results and discussion}

\subsection{Adsorption studies}

The representative adsorption isotherms of natural and the calcined zeolites (for wash-water temperature of $50^{\circ} \mathrm{C}$ ) for 60 and $180 \mathrm{~min}$ are shown in the Figs. 3 and 4, respectively. The adsorption isotherms are of type II according to IUPAC classification [31]. The nitrogen adsorption on natural and the calcined zeolites is very low. A comparison of Figs. 3 with 4 shows that the nitrogen adsorption capacity increases, as the calcination period is increased. The adsorption data were used to calculate the surface area, $A_{\mathrm{BET}}$, external surface area, $A_{\text {ext }}$, micropore volume, $W_{\mathrm{o}}$, maximum amount adsorbed, $V_{\max }$, and half-width of the slit like pore, $x$, of the natural and the calcined zeolites [32,33]. Even the natural zeolite is the microporous material, the characterized adsorption properties from nitrogen adsorption at $77 \mathrm{~K}$ are very low $\left(A_{\mathrm{BET}}=36.03 \mathrm{~m}^{2} / \mathrm{g}, A_{\mathrm{ext}}=36.03 \mathrm{~m}^{2} / \mathrm{g}, W_{\mathrm{o}}=\right.$ 


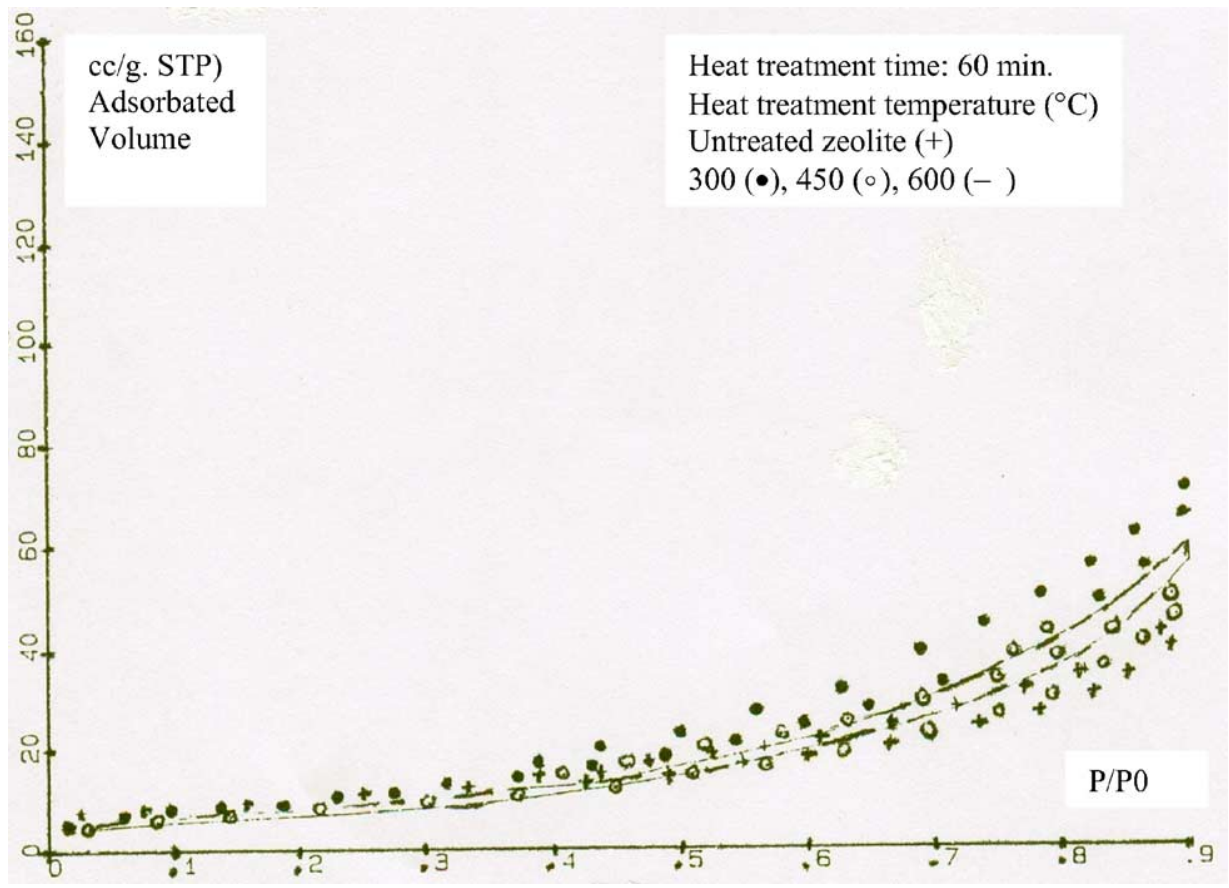

Fig. 3. Nitrogen adsorption isotherms for natural and heat-treated zeolites $(t=60 \mathrm{~min})$.

$0.0142 \mathrm{~m}^{3} / \mathrm{g}, V_{\max }=0.063 \mathrm{~m}^{3} / \mathrm{g}, x=10.69 \AA$ ) because of the presence the impurities blocking the channels in zeolite crystals. In the calcined zeolites, the micropous structure can not be detected with nitrogen adsorption. The mesoporous and macroporous structure seem to be improved especially up to $450{ }^{\circ} \mathrm{C}$. This can be explained with the migration of a part of the charge-balancing cations and aluminum outside the channel which compose the crystal of the zeolite, re- stricting the accessibility of nitrogen. During the calcination the shrinkage of the unit cell of the crystals is expected as well. The increase in the $V_{\max }, A_{\mathrm{BET}}$ and $A_{\text {ext }}$ values with increasing the period of time was observed. For $60 \mathrm{~min}$ treatment, the external surface area, $A_{\text {ext }}$ values were increased to 37.67 and $48.72 \mathrm{~m}^{2} / \mathrm{g}$ with increasing calcination temperature to 300 and $450^{\circ} \mathrm{C}$, respectively. Similar increase was observed for $180 \mathrm{~min}$, but the $A_{\text {ext }}$ values were higher; 61.21

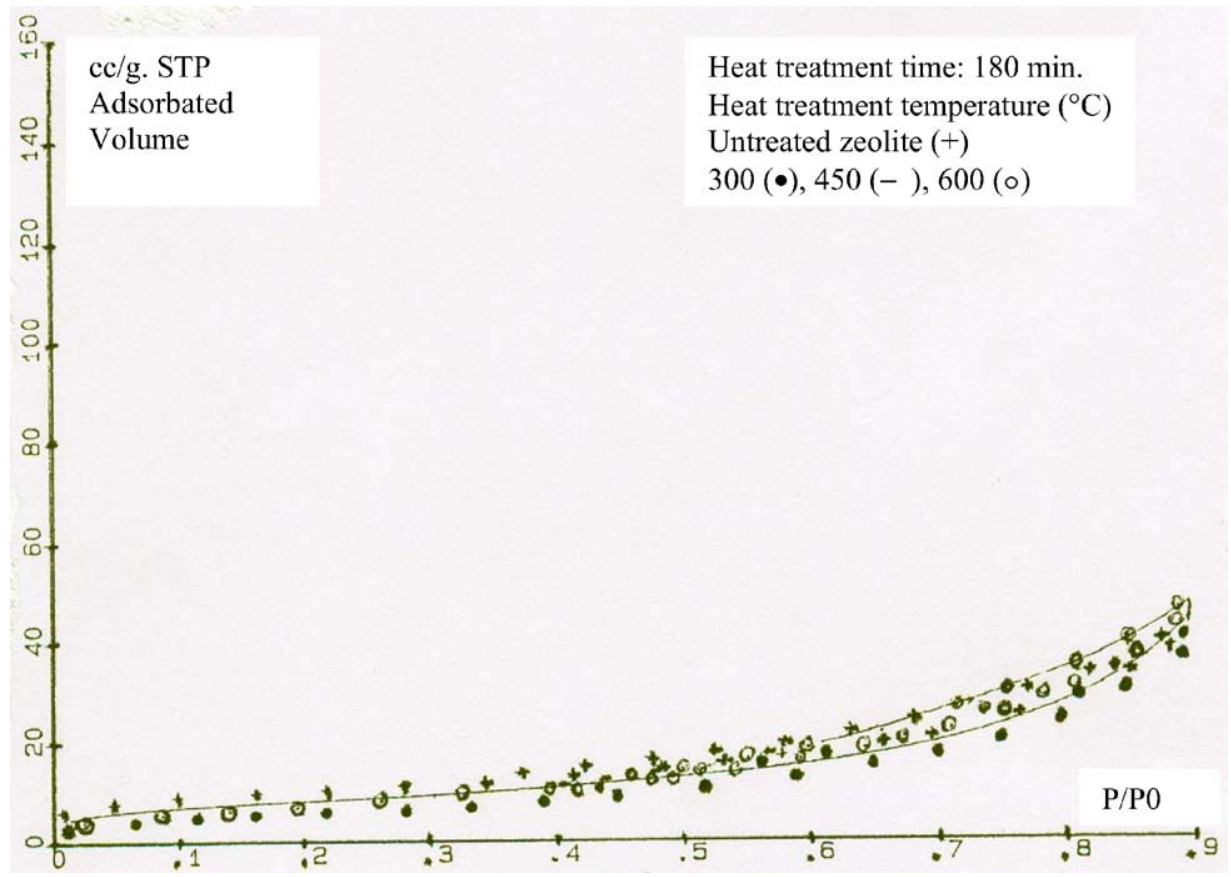

Fig. 4. Nitrogen adsorption isotherms for natural and heat-treated zeolites $(t=180 \mathrm{~min})$. 


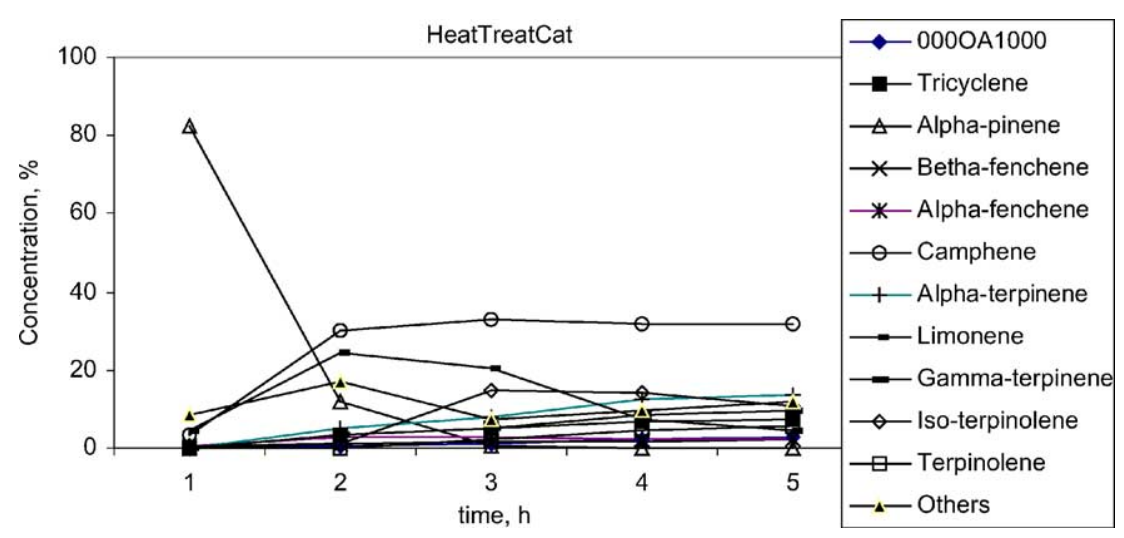

Fig. 5. Isomerization of $\alpha$-pinene over natural zeolite at $155^{\circ} \mathrm{C}$.

and $75.07 \mathrm{~m}^{2} / \mathrm{g}$ at 300 and $450{ }^{\circ} \mathrm{C}$, respectively. Thereafter, by increasing the calcination temperature to $600^{\circ} \mathrm{C}$, the $V_{\max }, A_{\mathrm{BET}}$ and $A_{\text {ext }}$ values were decreased to $0.073 \mathrm{~cm}^{3} / \mathrm{g}$, 29.38 , and $39,25 \mathrm{~m}^{2} / \mathrm{g}$ for $60 \mathrm{~min}$ and $0.074 \mathrm{~cm}^{3} / \mathrm{g}, 29.38$ and $50.90 \mathrm{~m}^{2} / \mathrm{g}$ for $180 \mathrm{~min}$. This indicates that the crystalline phase was collapsed damaging the lattice due to calcination at $600{ }^{\circ} \mathrm{C}$. The half-width of the pores can only be calculated for the calcined zeolite at $300^{\circ} \mathrm{C}$ for $60 \mathrm{~min}$ as $13.39 \AA$.

\subsection{Reaction studies}

The typical kinetic curves are presented in Fig. 5. The main reaction products in accordance to the previous studies were camphene and limonene while tricyclene, fenchene, terpinolene, $p$-cymene, $\alpha$ - and $\gamma$-terpinene were also formed.

In these experiments total conversion of $\alpha$-pinene $\left(X_{\mathrm{T}}\right)$, conversion to camphene $\left(X_{\mathrm{C}}\right)$, conversion to limonene $\left(X_{\mathrm{L}}\right)$ and selectivities to camphene $\left(S_{\mathrm{C}}\right)$ and limonene $\left(S_{\mathrm{L}}\right)$ were determined in the following ways:

$X_{\mathrm{T}}=\frac{\text { moles of converted } A}{\text { initial moles of } \alpha \text {-pinene }} \times 100$

$X_{\mathrm{C}}$ or $X_{\mathrm{L}}=\frac{\text { moles of formed } C \text { or } L}{\text { initial moles of } \alpha \text {-pinene }} \times 100$

$S_{\mathrm{C}}$ or $S_{\mathrm{L}}=\frac{\text { moles of } \operatorname{product}(C \text { or } L) \text { formed }}{\text { moles of converted } \alpha \text {-pinene }} \times 100$

Table 1 presents total conversion of $\alpha$-pinene $\left(X_{\mathrm{T}}\right)$, conversion to camphene $\left(X_{\mathrm{C}}\right)$, conversion to limonene $\left(X_{\mathrm{L}}\right)$ and selectivities to camphene $\left(S_{\mathrm{C}}\right)$ and limonene $\left(S_{\mathrm{L}}\right)$.

Total conversion of $\alpha$-pinene which is a measure of catalytic activity of catalysts prepared decreases with increasing calcination temperature. This is probably due to the fact that the calcination procedure leads to a loss of some acid sites. Therefore, conversion of $\alpha$-pinene which is an acid-catalysed reaction, decreases.

In general, calcination time causes a decrease in the total conversion of $\alpha$-pinene for samples with wash-water temperature of $50^{\circ} \mathrm{C}$, but it was not observed a regular change in total conversion with increasing calcination time for sam- ples with wash-water temperature of $25^{\circ} \mathrm{C}$. The increase in wash-water temperature from 25 to $50^{\circ} \mathrm{C}$ causes a decrease in total conversion of $\alpha$-pinene, probably due to the removal of some catalytically active impurities from zeolite structure (Fig. 6).

At low conversions of $\alpha$-pinene, limonene and camphene are formed as main products. Tricyclene is produced by slow isomerization of camphene as an equilibrium product. At high conversions of $\alpha$-pinene, limonene isomerizes into secondary products, when $\alpha$-pinene is totally consumed, camphene and tricyclene have almost equilibrium concentration.

Fig. 7 presents the concentrations of camphene and tricyclene as a function of $\alpha$-pinene conversion for all catalysts prepared. It is seen that selectivity to camphene and tricyclene which are the bi- and tricyclic products, respectively, was almost independent of conversion of $\alpha$-pinene on all studied catalysts irrespectively of the pre-treatment of zeolite. Similar dependencies were already reported in the literature $[14,20,22,27]$.

However, selectivity to limonene was very much dependent on conversion over the zeolites calcined at $300^{\circ} \mathrm{C}$ due to secondary reactions of limonene.

Fig. 8 shows this dependency. For conversions lower than about $80 \%$, the amount of limonene increases with

Table 1

Conversion and selectivity values calculated for different heat-treated zeolite catalysts in $\alpha$-pinene isomerization

\begin{tabular}{llllll}
\hline Catalyst & $X_{\mathrm{T}}$ & $X_{\mathrm{C}}$ & $X_{\mathrm{L}}$ & $S_{\mathrm{C}}$ & $S_{\mathrm{L}}$ \\
\hline 000OA1000 & 1.00 & 0.35 & - & 0.35 & - \\
300OA1060 & 0.88 & 0.38 & 0.30 & 0.43 & 0.34 \\
300OA1180 & 0.97 & 0.40 & 0.19 & 0.41 & 0.20 \\
450OA1060 & 0.74 & 0.28 & 0.27 & 0.38 & 0.37 \\
450OA1180 & 0.66 & 0.21 & 0.66 & 0.32 & 0.37 \\
600OA1060 & 0.29 & 0.10 & 0.14 & 0.36 & 0.48 \\
600OA1180 & 0.50 & 0.16 & 0.17 & 0.33 & 0.35 \\
300OA2060 & 1.00 & 0.39 & 0.25 & 0.39 & 0.25 \\
300OA2180 & 0.84 & 0.34 & 0.27 & 0.41 & 0.32 \\
450OA2060 & 0.59 & 0.20 & 0.21 & 0.33 & 0.36 \\
450OA2180 & 0.54 & 0.16 & 0.20 & 0.30 & 0.37 \\
600OA2060 & 0.25 & 0.08 & 0.13 & 0.34 & 0.51 \\
600OA2180 & 0.42 & 0.14 & 0.16 & 0.32 & 0.37 \\
\hline
\end{tabular}



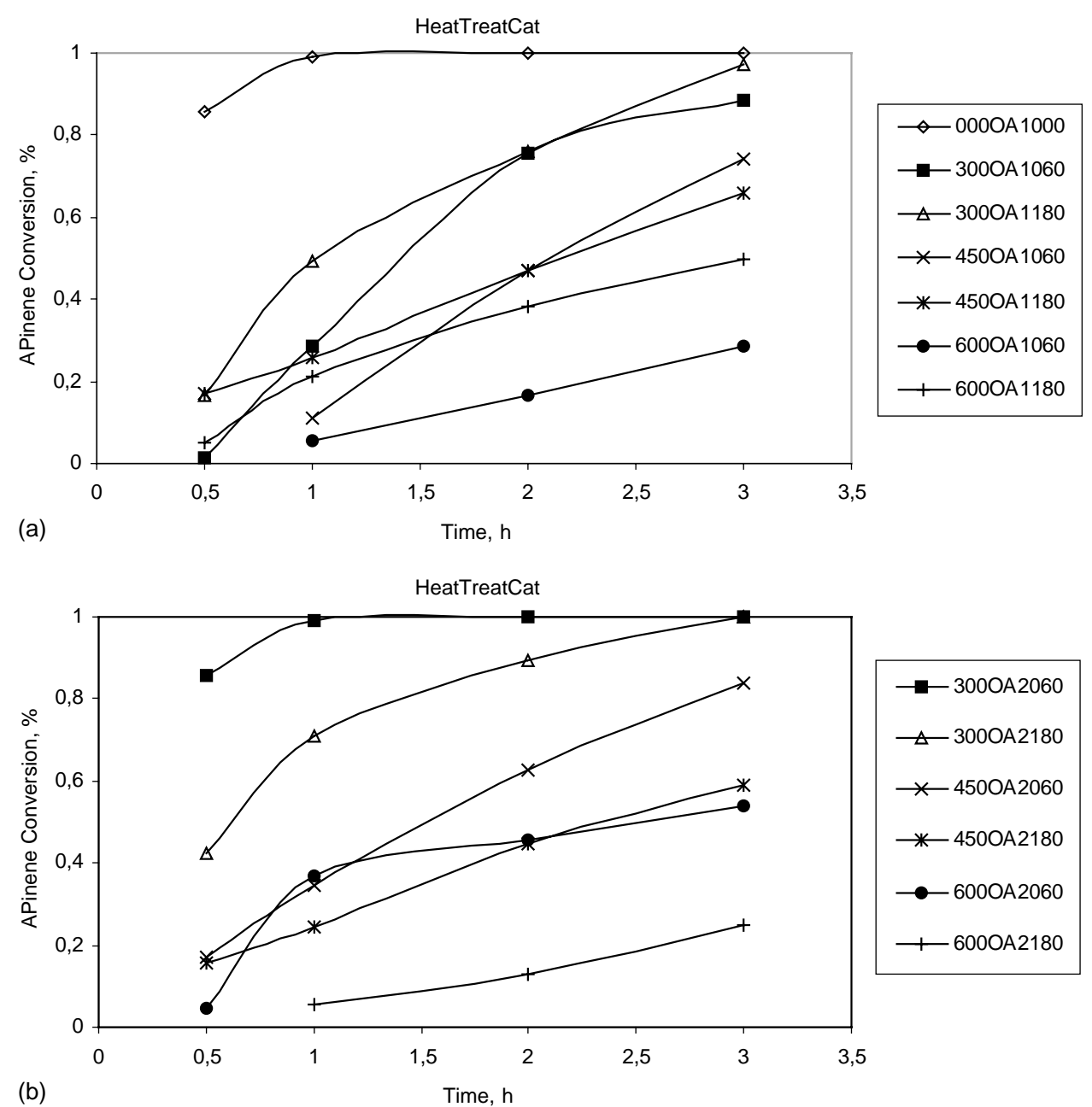

Fig. 6. The effect of calcination temperature on total conversion of $\alpha$-pinene (heating for 60 and $180 \mathrm{~min}$ ).

conversion over the zeolites calcined at $300{ }^{\circ} \mathrm{C}$. At higher conversion levels, limonene yield decreases which means that secondary reactions of limonene proceed faster. However, such a decrease in limonene amount is not observed over zeolites calcined at 450 and $600{ }^{\circ} \mathrm{C}$. Because these catalysts are not as active as the ones calcined at $300^{\circ} \mathrm{C}$. Fig. 8 presents the change in limonene concentration as a function of $\alpha$-pinene conversion for zeolites calcined at $600{ }^{\circ} \mathrm{C}$ as well.
Fig. 9 presents the product distribution as a function of $\alpha$-pinene conversion over zeolite treated at $300^{\circ} \mathrm{C}$. Products with a retention time lower than $\alpha$-pinene were designated as "low retention time products" (LRTP) products with higher retention times than terpinolene as "high retention time products" (HRTP) and the products in the range between $\alpha$-pinene and terpinolene as "unidentified products" (UP). As seen from the figure, as $\alpha$-pinene conversion increases, the yields of terpinenes and terpinolenes also

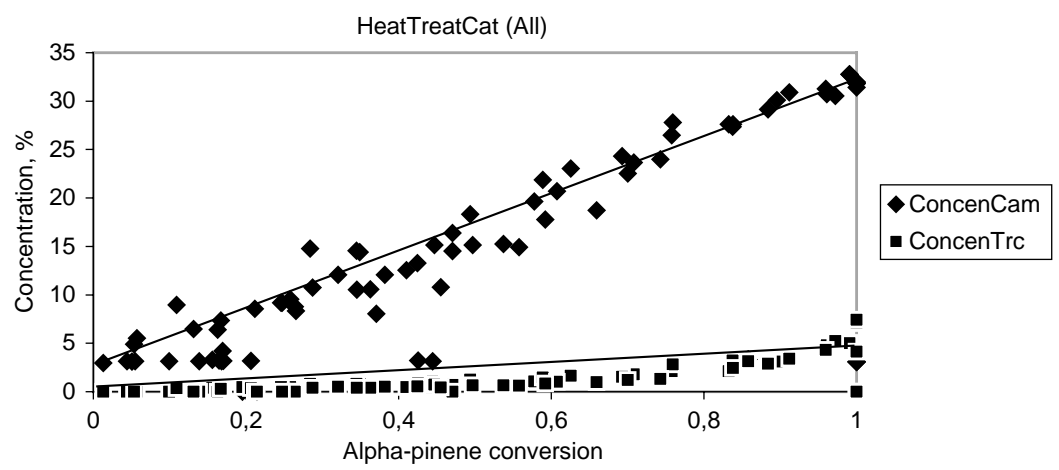

Fig. 7. Concentrations of camphene and tricyclene as a function of $\alpha$-pinene conversion for all catalysts prepared. 

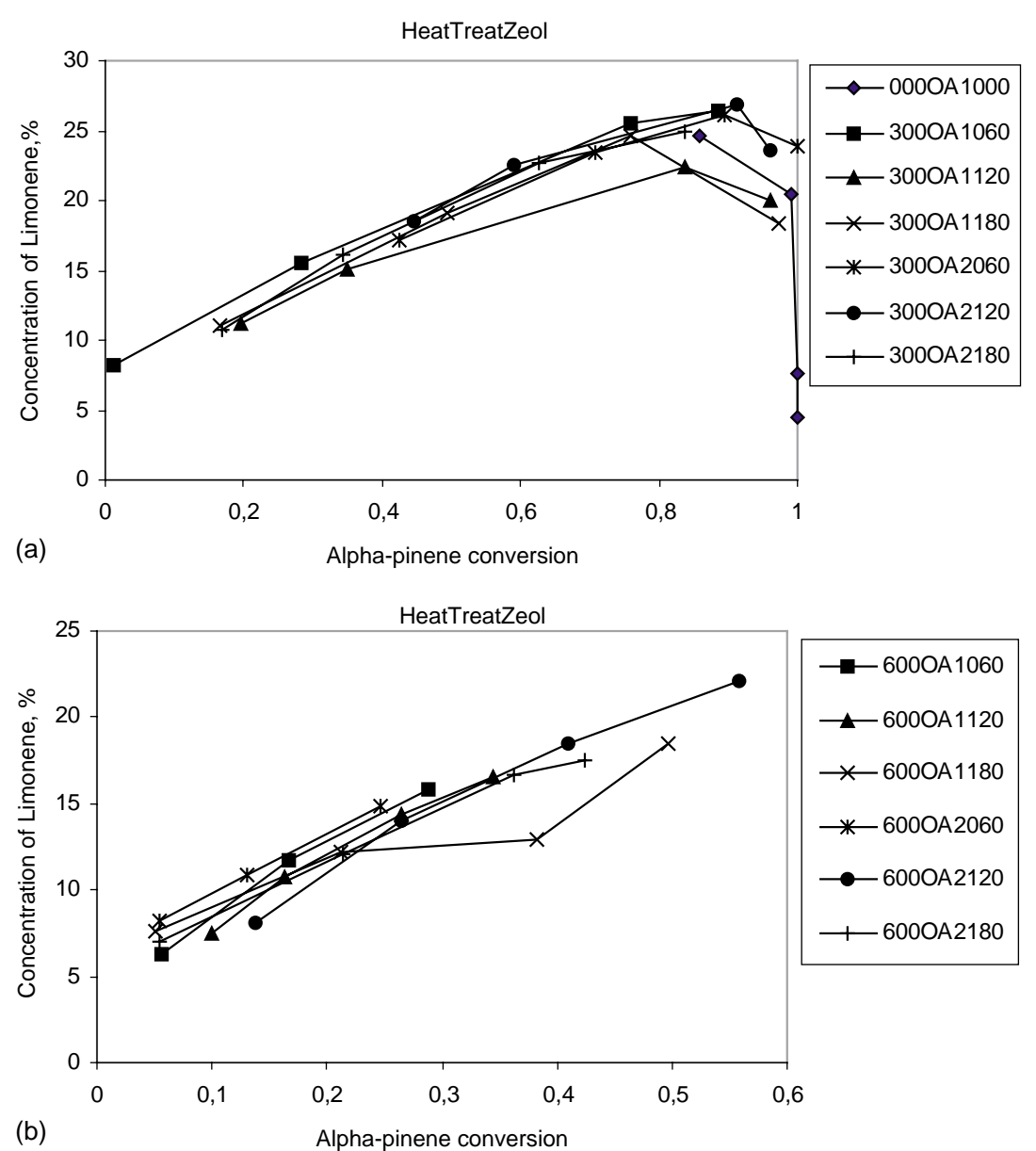

Fig. 8. Limonene mole fraction as a function of $\alpha$-pinene conversion over zeolites calcined at 300 and $600{ }^{\circ} \mathrm{C}$.

increase. This result is observed over zeolites treated at 450 and $600{ }^{\circ} \mathrm{C}$ as well. Fig. 10 shows that high retention time products and unidentified products increase with increasing calcination temperature. This figure gives the final concentrations of products in the reaction mixtures after a reaction time of $3 \mathrm{~h}$ for different calcination temperatures of the catalysts. The half-width of pores, $x$, increases with increasing calcination temperature; for example, $x$ is 10.69 and $13.39 \AA$, respectively, for natural zeolite and calcined at $300{ }^{\circ} \mathrm{C}$ for $60 \mathrm{~min}$ as stated in Section 3.1. That is, the larger pore sizes facilitate the formation of bulky intermediates required for forming polymeric products, HRTPs. Bulky intermediates are obtained from disproportionation reactions of terpinenes and terpinolenes. This result is in good accordance with literature [14].

\subsection{Kinetic studies}

Isomerization of $\alpha$-pinene was reported to be of zero order by Rudakov et al. [34], to be of first-order by Allahverdiev et al. [24] and Özkan et al. [27]. Elementary step of mechanism was advanced and selectivity was modelled on the basis of it. In the present study, for kinetic analysis the following rate equations were tested for reaction data over each calcined zeolite catalyst.

$\frac{-\mathrm{d} C}{\mathrm{~d} t}=k C, \quad n=1$ first-order kinetic

$\frac{C_{A}^{1-n}-C_{A 0}^{1-n}}{n-1}=k t, \quad n \neq 1$ order different from 1

Eqs. (1) and (2) for $n=0,0.5,1.3$, etc. were tested. Fig. 11 presents the results of Eq. (1) for heat-treated samples with wash-water temperature of $25^{\circ} \mathrm{C}$. Reaction rate constants were found to be $0.87,0.33$ and $0.19 \mathrm{~h}^{-1}$ for samples calcined at 300,450 and $600^{\circ} \mathrm{C}$, respectively. The rate constants obtained includes the experimental data for all durations (60 and $180 \mathrm{~min}$ ) of a mentioned calcination temperature. A first-order dependency on $\alpha$-pinene consumption fits the experimental data quite well. Regression coefficient was much greater than 0.90 when the calculations were done for a catalyst sample calcined at any individual temperature and calcination duration. As seen, reaction rate constant decreases with increasing calcination temperature because of the decrease in catalytic activity of catalyst. No change in colour of catalyst particles was observed indicating that catalyst deactivation does not occur during kinetic experiments. 

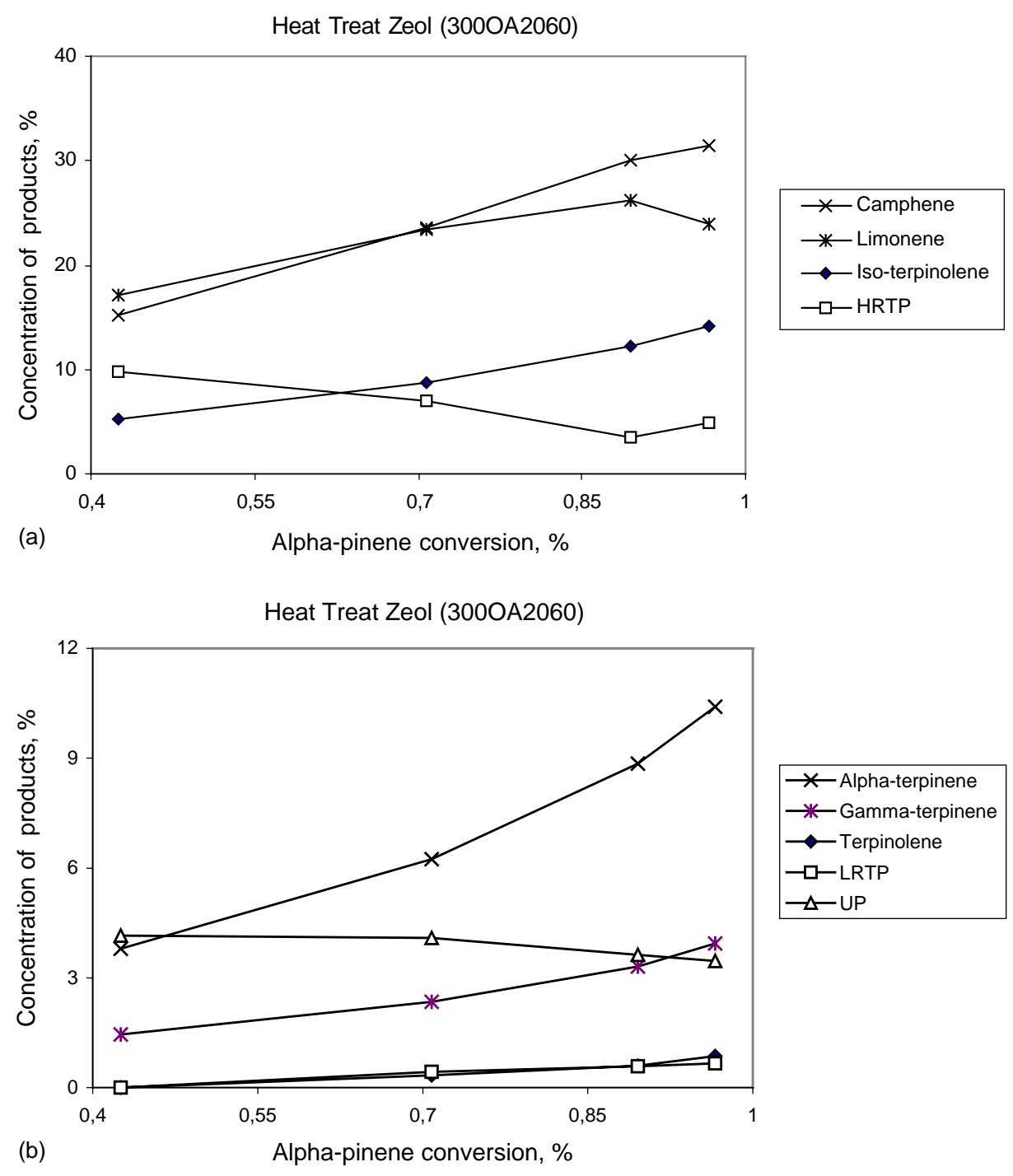

Fig. 9. Concentrations of products as a function of $\alpha$-pinene conversion for the catalyst calcined at $300^{\circ} \mathrm{C}$. (a) Camphene, limonene, iso-terpinolene, HRTP; (b) $\gamma$-terpinene, $\alpha$-terpinene, terpinolene, LRTP, UP.

\subsection{IR studies}

Infrared spectroscopy has been used successfully for studying zeolite structure and properties. Asymmetrical stretching vibrations of internal tetrahedral linkages due to $\mathrm{Si}-\mathrm{O}-\mathrm{Al}$ bondings in the framework $\left(1060 \mathrm{~cm}^{-1}\right)$, internal tetrahedral $\mathrm{T}-\mathrm{O}$-bending $\left(460 \mathrm{~cm}^{-1}\right)$ and external tetrahedral double ring due to $\mathrm{O}-\mathrm{T}-\mathrm{O}$ bending $\left(600 \mathrm{~cm}^{-1}\right)$, the $\mathrm{T}-\mathrm{O}$ asymmetric stretching vibration of free tetrahedral $\left(1202-1212 \mathrm{~cm}^{-1}\right)$ and external tetrahedral linkage symmetric stretching $\left(795 \mathrm{~cm}^{-1}\right)$ are the characteristics for the clinoptilolite mineral. Among the other bands, external tetrahedra double ring vibration was selected as the representative band for the clinoptilolite dedection [35].

Fig. 12(a) presents the effect of heat treatment process on IR spectra band intensities of calcined zeolite samples.
As seen in the figure, the peak heights of all the bands increased by heat treatment at 300 and $450{ }^{\circ} \mathrm{C}$, comparison with natural zeolite. The highest increase is obtained at $1060 \mathrm{~cm}^{-1}$ strong band that shows asymmetric vibrations. Lower intensities are observed in all the bands during the heat treatment at $600^{\circ} \mathrm{C}$, probably due to the collapse of the porous structure, which is also supported by XRD analysis. The disappearance of the characteristic band for clinoptilolite and the band at $1635 \mathrm{~cm}^{-1}$ due to the bending vibration mode of water with heat treatment at $600^{\circ} \mathrm{C}$ related to removal zeolitic water and partly loss of Lewis sites from the structure. The considerable decrease in the intensity in the region of the $3400-3700 \mathrm{~cm}^{-1}$ with heat treatment of zeolite at $600^{\circ} \mathrm{C}$ can also be seen from the figure. The band at $3687 \mathrm{~cm}^{-1}$, assigned to hydroxyl groups (Bronsted sites) almost disappear and only a band at about $3420 \mathrm{~cm}^{-1}$ corresponding to water adsorbed by free silica is observed with 

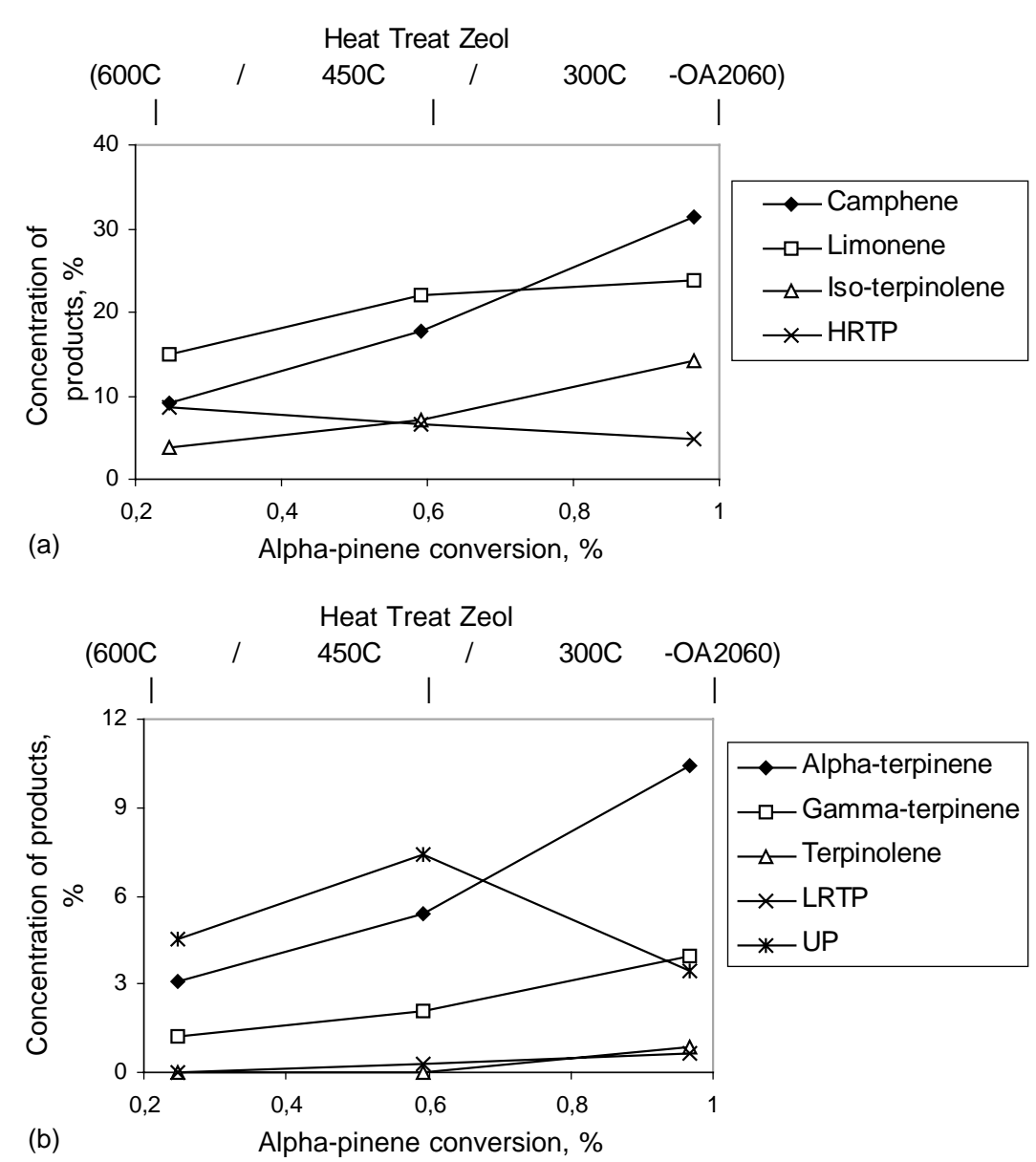

Fig. 10. Concentrations of products as a function of $\alpha$-pinene conversion for the catalysts prepared at different temperatures. (a) Camphene, limonene, iso-terpinolene, HRTP; (b) $\gamma$-terpinene, $\alpha$-terpinene, terpinolene, LRTP, UP.

very low intensity in the heat-treated zeolites at $600^{\circ} \mathrm{C}$. In this situation, it is possible to say that tedrahedra is collapsed by removal of zeolitic water when calcinations is applied at higher temperatures than $450{ }^{\circ} \mathrm{C}$. A decrease in peak intensities with heating time was also observed. The relative intensities of the band at $600 \mathrm{~cm}^{-1}$ according to those at $1060,780,460 \mathrm{~cm}^{-1}$ are indicated in Fig. 12(b). It was observed that the relative intensities decreased with the thermal treatment indicating the loss of clinoptilolite content in the sample.

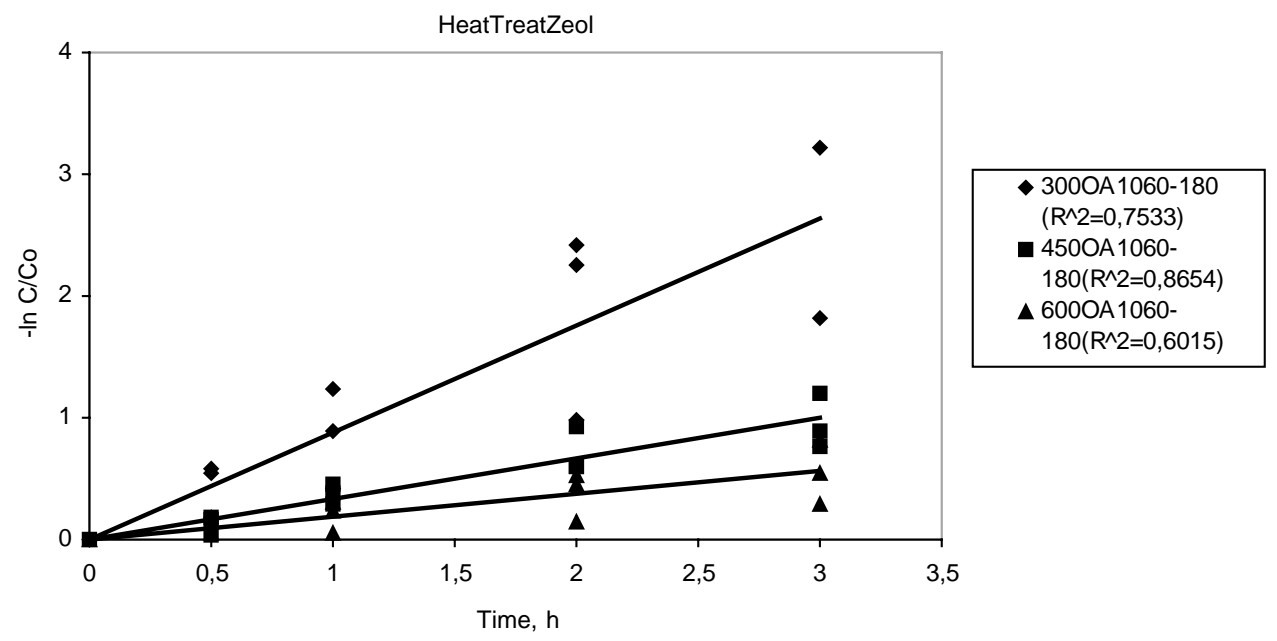

Fig. 11. First-order dependency on $\alpha$-pinene consumption for heat-treated zeolites. 

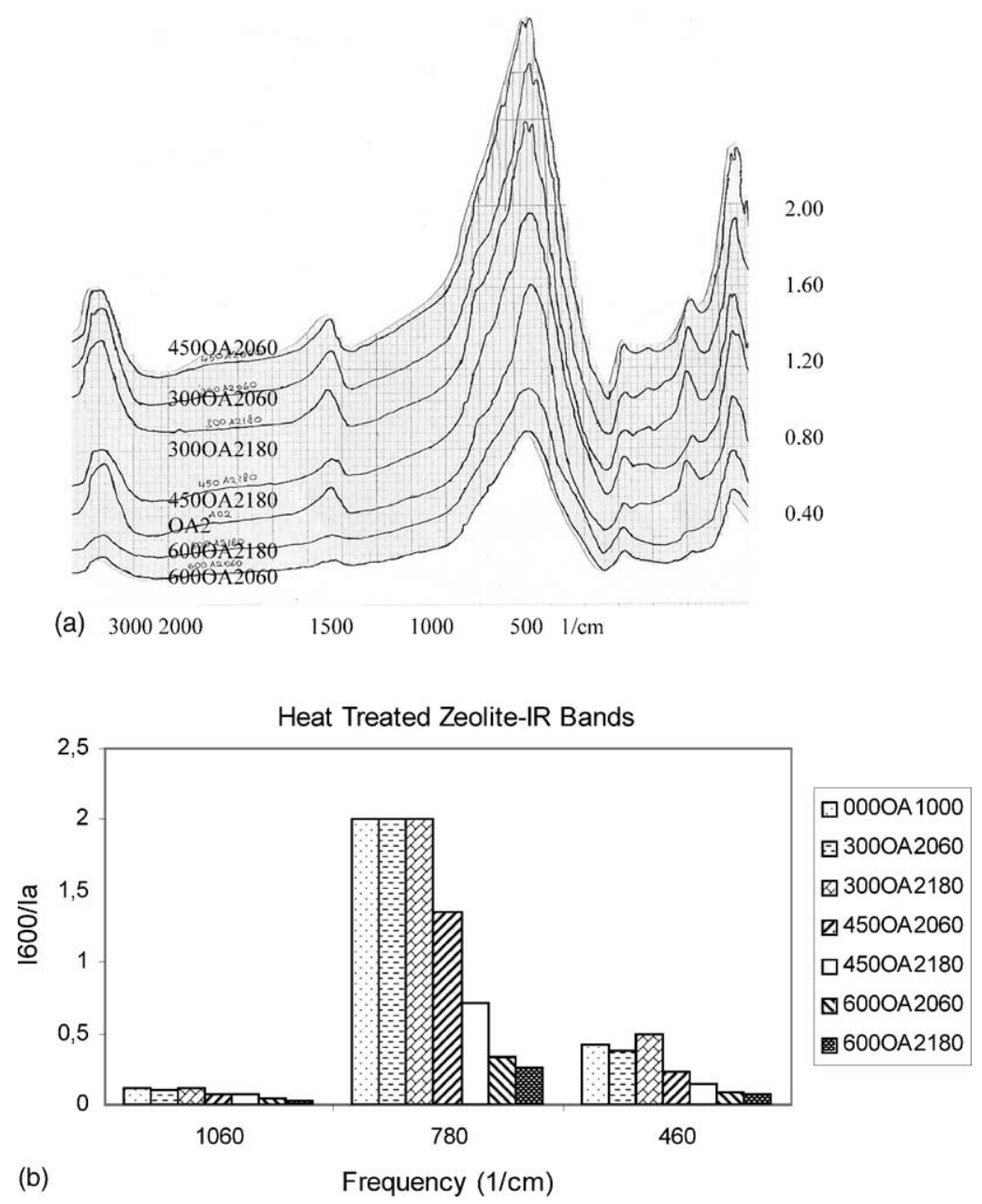

Fig. 12. (a) IR spectra of natural zeolite samples calcined at 300,450 and $600{ }^{\circ} \mathrm{C}$ (wash-water temperature: $50{ }^{\circ} \mathrm{C}$ ); $($ b) effect of heat treatment temperature on relative intensities of IR spectra of heat-treated zeolites samples (wash-water temperature: $50^{\circ} \mathrm{C}$ ).

\subsection{XRD studies}

Fig. 13 illustrates the XRD patterns of some zeolite samples calcined at different temperatures. A sharp destruction in zeolite structure was observed with increasing calcination temperature from 300 to $600^{\circ} \mathrm{C}$. Characteristic peaks of clinoptilolite at about $2 \theta=22.5^{\circ}, 2 \theta=17.5^{\circ}$ and $2 \theta=13^{\circ}$ almost disappear with the increase in calcination temperature. XRD reflections were supported by nitrogen adsorption and IR spectra of samples. BET surface area, maximum amount of nitrogen adsorbed were decreased with the increase of calcination temperature to $600{ }^{\circ} \mathrm{C}$, because the crystalline phase was collapsed.

\subsection{Acidity studies}

Tables 2 and 3 present the acid strengths and the amount of acid sites of some heat-treated natural zeolite samples. Tables 2 and 3 also show the intensities of IR spectra of pyridine adsorbed samples at given wave numbers for some catalysts prepared. The range of the acid strength of natu- ral zeolite was found to be +5.00 to +3.30 [36]. It means that range of the acid strength broadens from 5.00-3.30 to 6.8-0.80 with calcination. The amount of acid sites of the heat-treated natural zeolites at the same heating duration decreases with the temperature increase. This situation points out us that the calcination causes the loss of some acid sites. Brönsted acidity presents a decrease after a maximum at calcination temperature of $450{ }^{\circ} \mathrm{C}$ while Lewis acidity in-

\section{Table 2}

The acid strengths of samples, $H_{0}$, number of acid sites at related $H_{0}$ values in terms of consumption of diethylamine and total number of acid sites

\begin{tabular}{|c|c|c|c|c|}
\hline \multirow[t]{2}{*}{ Catalyst code } & \multicolumn{3}{|c|}{$\begin{array}{l}\text { Consumption of diethylamine } \\
\text { (mmol titrant/g cat) }\end{array}$} & \multirow{2}{*}{$\begin{array}{l}\text { Total number } \\
\text { of acid sites } \\
6.8-0.80\end{array}$} \\
\hline & $H_{0}=6.8$ & $H_{0}=0.80$ & $<0.80$ & \\
\hline 300OA1060 & 0.189 & 0.119 & 0.010 & 0.318 \\
\hline 300OA1180 & 0.271 & 0.159 & 0.000 & 0.430 \\
\hline 450OA1060 & 0.168 & 0.132 & 0.000 & 0.300 \\
\hline 450OA1180 & 0.236 & 0.154 & 0.000 & 0.390 \\
\hline 600OA1060 & 0.154 & 0.091 & 0.015 & 0.260 \\
\hline $600 \mathrm{OA} 1180$ & 0.163 & 0.108 & 0.000 & 0.271 \\
\hline
\end{tabular}



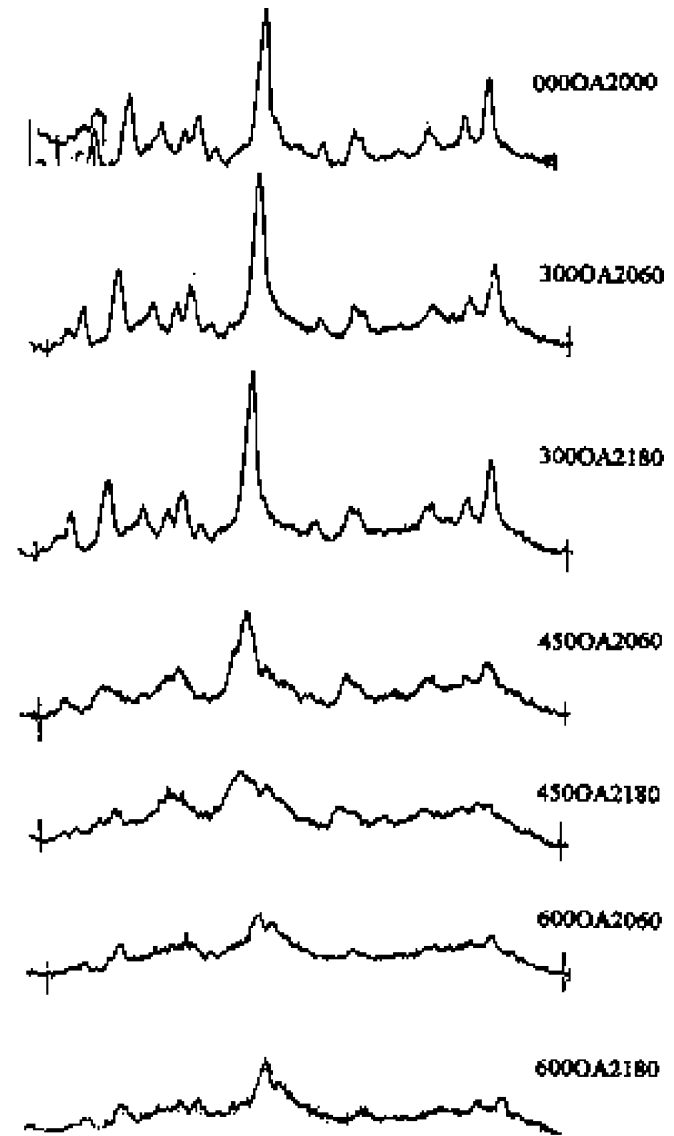

343230282624222018161412100806

Fig. 13. XRD patterns of some heat-treated zeolites.

creases after a minimum at $450{ }^{\circ} \mathrm{C}$ for a calcination time of $60 \mathrm{~min}$. These results confirm the ones given in the literature for $\mathrm{NH}_{4} \mathrm{Y}$ zeolite [28], whereas a continuous decrease in Lewis and Brönsted acidity is observed with samples calcined for $180 \mathrm{~min}$.

Fig. 14 shows how the selectivity of camphene and limonene over heat-treated zeolites change with L/B increase for both reaction time of 0.5 and $3 \mathrm{~h}$. Selectivity to limonene was not shown for a reaction time of $3 \mathrm{~h}$, because high amounts of limonene are consumed for the secondary reactions of limonene after a reaction time of $3 \mathrm{~h}$. At a reaction time of $0.5 \mathrm{~h}$ selectivity to camphene and limonene over

Table 3

The intensities IR spectra of pyridine adsorbed samples at given wave numbers

\begin{tabular}{llll}
\hline Catalyst code & $\begin{array}{l}\text { Lewis }(\mathrm{L}) \\
\left(\text { at } 1450 \mathrm{~cm}^{-1}\right)\end{array}$ & $\begin{array}{l}\text { Bronsted }(\mathrm{B}) \\
\left(\text { at } 1545 \mathrm{~cm}^{-1}\right)\end{array}$ & $\mathrm{L} / \mathrm{B}$ \\
\hline 300OA1060 & 0.036 & 0.0338 & 1.065 \\
300OA1180 & 0.065 & 0.038 & 1.71 \\
450OA1060 & 0.0194 & 0.0598 & 0.324 \\
450OA1180 & 0.04 & 0.0096 & 4.16 \\
600OA1060 & 0.048 & 0.012 & 4.0 \\
600OA1180 & 0.0016 & 0.008 & 0.2 \\
000OA1000 & 0.028 & 0.012 & 1.4 \\
\hline
\end{tabular}
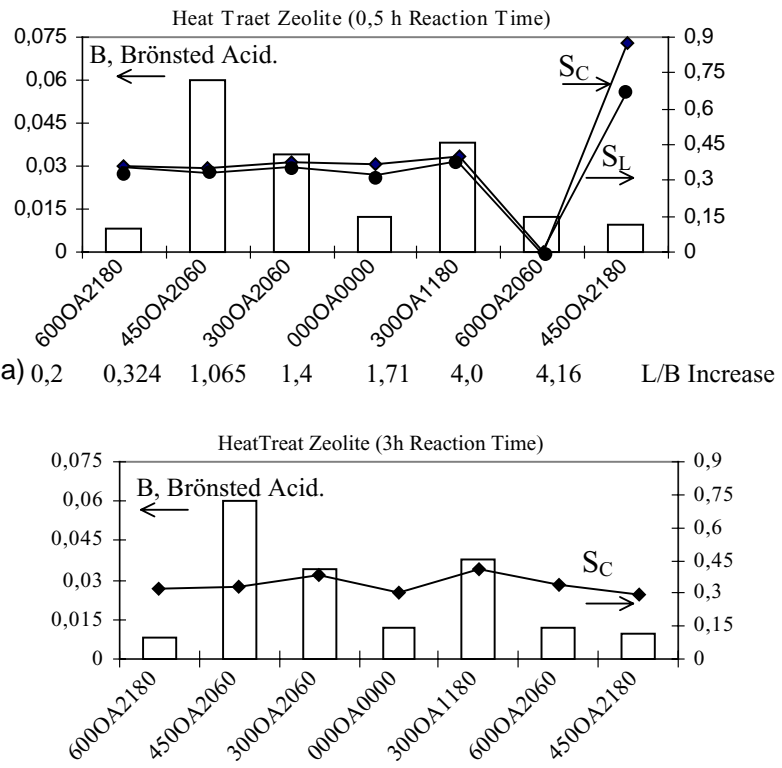

(b) $\quad 0,2 \quad 0,324 \quad 1,065 \quad 1,4 \quad 1,71 \quad 4,0 \quad 4,16 \quad$ L/B Increase

Fig. 14. The change of selectivity to camphene and limonene over heat-treated zeolites with L/B ratio and Bronsted acidity for a reaction time of (a) $0.5 \mathrm{~h}$; (b) $3 \mathrm{~h}$ (wash-water temperature: $50^{\circ} \mathrm{C}$ ).

the catalysts prepared are not influenced by L/B increase except the ones, 600OA1060 and 450OA1180. Selectivity to camphene over the catalyst $450 \mathrm{OA} 1180(\mathrm{~L} / \mathrm{B}=4.16)$ drastically increases with conforming the study reported by Severino et al. [16]. According to that study, camphene and bicyclic products are preferentially formed on the Lewis sites, as Lewis sites are weaker than Brönsted sites. Selectivity to camphene and limonene drop almost to zero over the catalyst $6000 \mathrm{~A} 1060$ probably, due to the collapse of the zeolite structure. To produce camphene, the catalyst should present Brönsted acidity, but not in very high or in very low amounts. For very high values of Brönsted acidity, catalyst is not very active for camphene formation. A slight decrease in camphene formation was obtained for low values of Brönsted acidity after a reaction time of $3 \mathrm{~h}$, Fig. 14(b). The effect of $\mathrm{L} / \mathrm{B}$ ratio on camphene selectivity was not observed in the range $\mathrm{L} / \mathrm{B}$ ratio studied for a reaction time of $3 \mathrm{~h}$ as well.

\section{Conclusion}

The liquid phase isomerization of $\alpha$-pinene over several differently pretreated natural zeolites was studied at atmospheric pressure in a batch reactor. It was observed that catalytic activity depended on the calcination procedure, that is, a decrease was observed with increasing calcination temperature. Selectivity to camphene was almost independent of conversion of $\alpha$-pinene, however selectivity to limonene was dependent very much on the conversion at $300{ }^{\circ} \mathrm{C}$ due to the secondary reactions of limonene, 
HRTP and UP increased with increasing calcination temperature.

The nitrogen adsorption results presented here suggested that on calcination the aluminum and charge balancing cation in the pore migrated on to the crystal of the natural zeolite leading to increase in the external surface area of the zeolites. However calcination at $600{ }^{\circ} \mathrm{C}$ caused to collapse of the structure, possible cracking the crystal as well.

\section{Acknowledgements}

We thank Ilhami Taskiran for GC analysis and Mehmet Akçay for IR measurements. This study is a part of a project supported by the Turkish Scientific Research Council under Project MISAG-120.

\section{References}

[1] G.V. Smith, et al., Stud. Surf. Sci. Catal. 101 (1996) 251.

[2] S.V. Korotov, V.A. Vyrodov, E.V. Afanas'eva, A.I. Kolesov, Z.L. Maslakova, T.D. Oblivantseva, P.K. Cheirkov, P.I. Zhurovlev, O.I. Minaeva, USSR Patent 238 541, 1969.

[3] E.V. Afanas'eva, V.A. Vyrodov, S.V. Korotov, Nauch Tr. 135 (1970) 11.

[4] E.V. Afanas'eva, V.A. Vyrodov, S.V. Korotov, Nauch Tr. 135 (1970) 20.

[5] Y. Matsubara, Y. Butani, S. Wakabayashi, Y. Watanabe, A. Takamatsu, M. Morita, Japanese Patent 28.575, 1970.

[6] A.A. Popov, V.A. Vyrodov, Lesokhim Prom-St. 6 (1979) 18.

[7] S.B. Battolova, T.R. Mukltanova, K.G. Tabenova, Vestn. Akad. Nauk. Kaz. SSR 10 (1990) 52.

[8] S. Kullaj, Bull. Shkoncave Nat. 39 (4) (1985) 47.

[9] S. Kullaj, Bull. Shkoncave Nat. 43 (1) (1989) 81.

[10] M. Nazir, M. Ahmed, F.M. Chaudhary, Pak. J. Sci. Ind. Res. 19 (1976) 175.

[11] W.F. Carson, US Patent 2382 397, 1945.

[12] W.J. Kirkpatrick, US Patent 2385 711, 1945.

[13] C.B. Davis, J.J. McBride, US Patent 3824 135, 1974.

[14] C.M. Lopez, F.J. Machado, K. Rodriguez, B. Mondez, M. Hasegawa, S. Pekerar, Appl. Catal. A: Gen. 173 (1998) 75.
[15] C.M. Lopez. F.J. Machado, K. Rodriguez, D. Harias, M. Hasegawa, in: A. Corma, F.V. Melo, S. Mendiroz, J.L.G. Fiero (Eds.), Studies in Surface Science and Catalysis, vol. 130D, Elsevier, Amsrsterdam, 2000, p. 3453.

[16] A. Severino, A. Esculcas, J. Rocha, J. Vital, L.S. Lobo, Appl. Catal. A: Gen. 142 (1996) 255.

[17] A.D. Stefanis, G. Perez, A.A.G. Tomlinson, Appl. Catal. A: Gen. 132 (1995) 353.

[18] T. Yamamoto, T. Matsuyama, T. Tanaka, T. Funabaki, S. Yoshida, Phys. Chem. Chem. Phys. 1 (1999) 2841.

[19] T. Yamamoto, T. Tanaka, T. Funabaki, S. Yoshida, J. Phys. Chem. B 102 (1999) 5830.

[20] T. Yamamoto, T. Matsuyama, T. Tanaka, T. Funabaki, S. Yoshida, J. Mol. Catal. A: Chem. 155 (2000) 271

[21] S. Fýndýk, G. Gündüz, JAOCS 74 (1997) 1145.

[22] A. Allahverdiev, G. Gunduz, D.Yu. Murzin, Ind. Eng. Chem. Res. 37 (1998) 2373.

[23] A. Allahverdiev, N.A. Sokolava, G. Gunduz, N.V. Kuilkova, Russ J. Phys. Chem. 72 (1998) 1647.

[24] A. Allahverdiev, S.B. Anderson, D. Yu. Murzin, Appl. Catal. A: Gen. 198 (1998) 197.

[25] O. Akpolat, G. Gündüz, in: L. Petrov. Ch. Boney, G. Kadinov (Eds.), Heterogeneous Catalysis, Varna, Bulagaria, 2000, p. 331.

[26] A.I. Allahverdiev, S. Irandoust, D.Y. Murzin, J. Catal. 185 (1999) 352.

[27] F. Özkan, G. Gündüz, O. Akpolat, N. Beşn, D.Yu. Murzin, Isomerization of $\alpha$-pinene over ion-exchanged natural zeolites, Chem. Eng. J. 91 (2003) 257-269.

[28] L. Grzona, N. Comelli, O. Masini, E. Ponzi, M. Ponzi, React. Kinet. Catal. Lett. 69/2 (2000) 271.

[29] J.W. Ward, J. Catal. 11 (1996) 238.

[30] K. Tanabe, M. Misone, Y. Ono, H. Hattori, in: B. Delman, J.T. Yates (Eds.), Study of Surface Science and Catalysis, vol. 51, 1989, p. 142.

[31] S. Brunauer, The Adsorption of Gases and Vapours, Princeton University Press, 1943.

[32] M.M. Dubinin, V.A. Astakhov, Adv. Chem. Senes. 102 (1970) 69.

[33] D.W. Breck, Zeolite Molecular Sieves, Wiley, New York, 1974.

[34] G.A. Rudakov, L.S. Ivanova, T.N. Pisareva, A.G. Borovskaya, Lesokhim, Gidroliz Prom. 4 (1975) 7.

[35] S.V. Goryainov, V.N. Stopolpovskaya, A.Y. Likhacheva, I.A. Belitsky, B.A., Fursenko, in: D.W. Ming, F.A. Mumpton (Eds.), Natural Zeolites 93: Occurrence, Properties, Use, 1995.

[36] E. Ünveren, Isomerization of $\alpha$-Pinene Over Acid-treated Natural Zeolite, Clinoptilolite, Master Thesis, Ege University, Izmir, Turkey, 2001. 